\title{
FELICIDAD Y VOCES DE MUJERES EN HEROIDAS DE OVIDIO
}

\author{
HAPPINESS AND WOMEN'S VOICES IN OVID'S HEROIDES
}

\author{
Alba BLÁZQUEZ NOYA \\ Universidad de Salamanca \\ albablazqueznoya@gmail.com
}

\begin{abstract}
Resumen: Las Heroidas de Ovidio han sido estudiadas en los últimos años como écriture féminine, puesto que las heroínas reescriben en sus cartas, ahora desde su perspectiva, las historias de sus vidas recogidas en los mitos y en la literatura. Desde este enfoque, el presente artículo estudia las voces de mujeres de las Heroidas con el fin de reflexionar sobre el modo en que cada una de esas voces que Ovidio presta a sus heroínas construye para sí el concepto de 'felicidad'. Por tanto, en un estudio intratextual, señalaremos las variaciones concretas del tema de la 'felicidad' existentes en las Heroidas de Ovidio, que unas veces podemos encontrar en positivo, cuando cada escritora habla de sus momentos de alegría, y otras veces podemos definirlas antitéticamente a partir de la expresión de su sufrimiento, que puede ser causado por el amor, el matrimonio, las convenciones sociales, la traición o la culpa.
\end{abstract}

Palabras clave: poesía latina; voces de mujeres; felicidad; Heroidas.

\begin{abstract}
In the last decades, Ovid's Heroides have been studied as écriture féminine, since the heroines re-write in their letters, now from their own perspective, the stories of their lives collected in myths and literature. From this point of view, this paper studies the female voices from the Heroides to reflect the way in which each one of the voices that Ovidio lends to its heroines constructs for itself the concept of 'happiness'. Therefore, in an intratextual study, we will point out the specific variations of the theme of 'happiness' that exist in Ovid's Heroides. These variations sometimes can be found in a positive way, when each writer speaks about their moments of joy, and other times can be defined antithetically from the expression of their suffering, which can be caused by love, marriage, social conventions, betrayal or guilt.
\end{abstract}

Keywords: latin poetry; women's voices; happiness; Heroides. 
as Heroidas de Ovidio han sido tradicionalmente definidas como una colección de cartas de amor que las heroínas de la mitología escriben a sus amados que están ausentes. Ellas suplican a sus amados su amor y su vuelta, les recuerdan sus momentos de felicidad, les reprochan todo lo que han hecho por ellos, que no cumplan sus promesas, que sean infieles (Moya, 1986: XXI). El poeta latino configura una obra de una enorme complejidad e interés literario que se puede resumir sucintamente en dos aspectos. Por un lado, se trata de cartas de carácter elegíaco en las que las heroínas se lamentan porque sus amados las han abandonado, y así, Ovidio presta a la heroína una voz y un medio subjetivo para que narre su versión de la historia prefijada de antemano en la tradición mitológica y literaria grecolatina. Por otro lado, al recoger historias mitológicas ya narradas en otros géneros literarios, especialmente en la épica y la tragedia, en la forma epistolar de las Heroidas se encuentran interesantes procesos intertextuales y numerosas adaptaciones de los géneros de partida.

La crítica más reciente ha tenido en cuenta estos aspectos, que han determinado las perspectivas metodológicas desde las que se ha abordado su estudio en las últimas décadas. Podemos resumir dos corrientes según su objeto de estudio principal. Tenemos en un primer lugar una corriente que se plantea los problemas de intertextualidad e intersección entre géneros literarios presentes en la obra ${ }^{1}$. La otra corriente estudia las cartas, utilizando conceptos críticos feministas y la perspectiva de 'género', como escritura de mujeres que reescriben desde sus personales puntos de vista las versiones literarias anteriores de sus historias (Lindheim, 2003; Spentzou, 2003; Fulkerson, 2005) ${ }^{2}$. Desde este enfoque, podemos adentrarnos en alguno de los temas que son transversales en la colección y por tanto susceptibles de ser estudiados desde una perspectiva intratextual, como, por ejemplo, el tema de la 'felicidad' en las Heroidas. Como define Bremond (2003: 168), el tema tiende a ejemplificar una noción que se supone definida sumergiéndola en el contexto de diversas situaciones, es decir, toma una entidad abstracta y hace de ella el punto de partida de una serie de variaciones concretas. Siguiendo los términos de esta definición, en el presente artículo reflexionamos sobre las 'variaciones concretas' del tema de la 'felicidad' que se recogen en las Heroidas de Ovidio, y, por lo tanto, trabajaremos desde la segunda perspectiva metodológica señalada realizando una aproximación al modo en que cada una de las voces que Ovidio les presta a sus heroínas construyen para sí el concepto de 'felicidad'3.

Como empezamos diciendo al principio de este artículo, las Heroidas han sido tradicionalmente definidas como una colección de cartas de amor que las heroínas de la mitología escriben a sus amados que las han abandonado. De tal definición se puede inferir que la voz de nuestras escritoras estará repleta de lamento por el abandono y el amor truncado, y que, por tanto, el amor será la causa de su

\footnotetext{
${ }^{1}$ Desde esta perspectiva las estudian Kenney (1982), Rosati (1993), Casali (1995), Jolivet (2000) y Barchiesi (2001), por citar solo a algunos.

${ }^{2}$ El resumen de las aproximaciones teóricas recientes de las Heroidas lo proporciona Cortés Tovar (2012: 248).

${ }^{3}$ El presente estudio intratextual se fundamenta en nuestros trabajos individualizados sobre las Heroidas basadas en tragedias (Blázquez Noya 2015, 2017a, 2017b y otros trabajos en proceso de publicación).
} 
sufrimiento y también de su felicidad. En efecto, hay mucho sufrimiento y lamento en las Heroidas, sin embargo, tras una lectura detenida, nos encontramos con que en raras ocasiones su dolor es producido puramente por el amor, sino que en la generación del sufrimiento de nuestras heroínas suelen actuar muchos otros factores, como veremos: el matrimonio, las convenciones sociales, la traición o el arrepentimiento. Hemos seleccionado las cartas de algunas de nuestras heroínas, Deyanira, Cánace, Hermione, Medea y Laodamía, para reflexionar sobre cómo el tema de la 'felicidad' se plasma en sus voces de dos formas diferentes: por un lado, las muestras de alegría en positivo que se desprenden de sus palabras, y por otro, los conceptos de 'felicidad' que se pueden definir por antítesis a partir de la expresión del sufrimiento de cada una y de sus deseos de alegría.

Empezaremos analizando la Heroida de Deyanira ${ }^{4}$, quien le escribe una carta a su esposo Hércules mientras espera su regreso después de enterarse de que ha enviado a la casa familiar a su nueva amante Yole 5 . Para entender la voz de esta heroína, resulta un buen punto de partida la perspectiva de Jacobson (1974: 240), quien opina que es una mujer casada con un gran hombre y que vive a través de la grandeza de su marido. Para ella, amar y ser amada sería de poca importancia. Lo que persigue es seguir compartiendo el honor de su marido, y para conseguirlo le incita a seguir comportándose como un héroe. Por tanto, la voz de Deyanira está totalmente influida por las convenciones sociales. A ella no le importa si su marido Hércules la ama ${ }^{6}$, lo que anhela es que sea un buen esposo. De las palabras de Deyanira se puede inferir que su matrimonio con Hércules le trae un tremendo dolor, una gran infelicidad, principalmente por dos causas. La primera, es que ella se está comportando como una buena esposa preocupada y modélica mientras su marido está constantemente fuera de casa enfrentándose a sus famosas hazañas, y por tanto, no cumpliendo con su deber matrimonial (Ov.Her.IX.27-47):

\footnotetext{
Mi marido está siempre lejos, tanto que lo conozco más como huésped que como esposo, y monstruos y fieras terribles persigue.

Yo por mi parte en una casa vacía entregada a virtuosos votos

me atormento con el temor de que mi marido muera a manos de un encarnizado enemigo.

Vir mihi semper abest, et coniuge notior hospes

Monstraque terribiles persequiturque feras;

Ipsa domo uidua uotis operata pudicis

Torqueor, infesto ne uir ab hoste cadat (Ov.Her.IX,33-36) 7.
}

La segunda, es que la blanda actitud amorosa de Hércules en su aventura con sus amantes (la más reciente Yole y la anterior Ónfale ${ }^{8}$ ) le ha traído mala fama de mollis uir, de hombre afeminado

\footnotetext{
${ }^{4}$ Para más información sobre la voz de Deyanira en Heroidas de Ovidio, ver Blázquez Noya (2015).

${ }^{5}$ El mito es el siguiente. Deyanira espera en Traquis a su marido Hércules mientras él, ausente desde hace tiempo, se enamora de Yole, princesa de Ecalia, conquista la cuidad y envía a su nueva amada como concubina a su casa con Deyanira. Esta, al verla, teme por su posición de esposa y envía a Hércules un manto impregnado con lo que ella piensa que es un filtro amoroso, pues así se lo presentó el centauro Neso cuando se lo entregó, pero resulta ser un fuerte veneno que acaba con él, y Deyanira se suicida.

${ }^{6}$ En las palabras de Deyanira no encontramos ninguna referencia a su amor por su marido, ni muestras de que anhele que él la ame.

${ }^{7}$ Seguimos la edición del texto latino de Moya (1986). Las traducciones son nuestras.

${ }^{8}$ Reina lidia al servicio de la cual estuvo Hércules como esclavo para pagar una deuda de sangre.
} 
que se ha dejado vencer por el amor, y eso es inaceptable para su esposo el héroe (Ov.Her.IX.1-26, 55-1189):

\author{
Me congratulo de que Ecalia se sume a nuestros triunfos, \\ lamento que el vencedor haya sucumbido ante la vencida. \\ Ha llegado de improviso a las ciudades pelasgas un rumor \\ deshonroso y que deben negar tus hechos. \\ A quien jamás Juno y su largo elenco de esfuerzos \\ dominaron, Yole le ha puesto el yugo. \\ Gratulor Oechaliam titulis accedere nostris; \\ Victorem uictae subcubuisse queror. \\ Fama Pelasgiadas subito peruenit in urbes \\ Decolor et factis infitianda tuis, \\ Quem numquam Iuno seriesque immensa laborum \\ Fregerit, huic Iolen imposuisse iugum (Ov.Her.IX.1-6).
}

Ya que tú no podrías serlo, con razón fue ella ${ }^{10}$ el hombre.

A ella eres tanto más inferior, cuanto que vencerte a ti, lo más grande del mundo, era mayor logro que vencer a los que tú venciste.

A aquella la promociona el tamaño de tus acciones:

Retírate ante los buenos, pues tu amiga es heredera de tu gloria.

¡Qué vergüenza! Las pieles erizadas arrancadas de las costillas del

duro león han cubierto su delicado costado.

Te engañas, y no sabes nada. No son aquellos los despojos del león, sino los tuyos, y tú sí que eres el vencedor de la fiera, pero aquella lo es de ti.

Quod tu non esses, iure uir illa fuit.

Qua tanto minor es, quanto te, maxime rerum,

Quam quos uicisti, uincere maius erat.

Illi procedit rerum mensura tuarum;

Cede bonis; heres laudis amica tuae.

O pudor! hirsuti costis exuta leonis

Aspera texerunt uellera molle latus.

Falleris et nescis; non sunt spolia illa leonis,

Sed tua, tuque ferae uictor es, illa tui (Ov.Her.IX.106-114).

La voz de Deyanira describe ambos elementos como propios del mal esposo, y, por consiguiente, de un matrimonio infeliz. De hecho, a partir de esta concepción del mal esposo y de la buena esposa, Deyanira elabora en forma de paremia su propia recomendación para la felicidad de las mujeres ${ }^{11}$ : «Mujer, si quieres casarte bien, cásate con un igual» (siqua uoles apte nubere, nube pari Ov.Her.IX.32 $2^{12}$ ). Vemos así que en el caso de Deyanira el elemento que causa -y arrebata- la felicidad es el matrimonio.

El matrimonio como factor de infelicidad no se encuentra aislado en la colección, pues el mismo tópico utiliza Cánace en su carta a Macareo. La historia de Cánace es una triste historia. Nuestra protagonista se enamoró de su hermano Macareo, con el que tuvo una relación amorosa de la que nació un hijo, algo que le trajo mucho sufrimiento dado que su padre castigó el incesto mandando asesinar

\footnotetext{
${ }^{9}$ Para más información sobre el afeminamiento de Hércules esclavizado por Ónfale, ver Blázquez Noya 2017 b.

${ }^{10}$ Ónfale.

${ }^{11}$ Para ampliar información, Blázquez Noya (2015: 19ss.).

${ }^{12}$ El verbo nubeo significa 'casarse la mujer'.
} 
al niño y ordenándola a ella que se suicidara. Cánace, que escribe su Heroida después de conocer el castigo, en determinado momento de su discurso olvida al interlocutor masculino, de la misma manera que hacía Deyanira, para dirigirse a sus hermanas, a las que dice: «Casaos con mejor suerte, felices hermanas» (Nubite felices Parca meliore sorores Ov.Her.XI.107 ${ }^{13}$ ). La infelicidad de Cánace no es por tanto tampoco fruto del desamor ${ }^{14}$, pues Macareo no ha dejado de amarla, sino que viene dada porque se unió con quien no debía y obtuvo un duro castigo por ello, de ahí que a sus hermanas les recomiende que se casen con alguien adecuado para seguir siendo felices. Por tanto, Deyanira y Cánace son ejemplos de cómo las voces de mujeres de las Heroidas recuerdan a otras mujeres que un buen matrimonio, ya sea con un buen marido que se comporte correctamente o con un buen marido bien visto socialmente, es la base para la felicidad.

El matrimonio de Hermione también le causa gran sufrimiento (Ov.Her.VIII). Ovidio presenta en su Heroida a una Hermione impotente y dócil completamente opuesta a anteriores versiones del personaje, especialmente a la Hermione de la Andrómaca de Eurípides, mujer autoritaria y arrogante (Murgatroyd, 2014: 852). Nuestra heroína, hija de Helena y Menelao, pese a que previamente había sido prometida por su abuelo a su primo Orestes, es finalmente entregada como esposa a Pirro ${ }^{15}$ tras la victoria de su padre en la Guerra de Troya. El sufrimiento que describe la Hermione ovidiana es causado por su matrimonio forzoso, otra convención social, en este caso la que establece el matrimonio como medio para sellar una relación de alianza. La mujer es, en el seno de una sociedad patriarcal y virilocal como la griega, un bien que circula entre familias, una pieza móvil dentro de la familia paterna, orientada para salir de la misma en el momento decisivo de su realización: el matrimonio. Y así, pasaba del control del padre al control del esposo (González García, 1996: 213). La carta de la Hermione ovidiana trata sobre esta convención y sobre cómo la heroína entra en negociación con ella. De su voz se desprende que ella desearía estar casada con Orestes, pero termina con Pirro en contra de su voluntad. Hermione, ya casada con Pirro, escribe una carta a Orestes para intentar convencerlo de que la rescate de Pirro, y así, utiliza la escritura como una herramienta para intentar cambiar su situación de sufrimiento:

Pirro, hijo de Aquiles, violento como su padre, me tiene encerrada en contra de la ley y la moral. Fui capaz de negarme a que me tomara bien dispuesta. Lo demás no lo consiguieron mis manos de mujer. «¿Qué haces Eácida? Tengo quien me reclame», le dije; «Pirro, tienes una muchacha con su propio dueño». Aquel, más sordo que el mar, me arrastró dentro de su casa mientras yo gritaba el nombre de Orestes con el cabello descuidado.

¿Habría soportado yo algo más grave como sierva si, tomada Lacedemonia, las hordas bárbaras hubieran raptado a las mujeres griegas? Con más cuidado golpeó a Andrómaca la Acaya vencedora cuando los fuegos dánaos quemaron las riquezas frigias ${ }^{16}$.

\footnotetext{
${ }^{13}$ Cánace utiliza también como Deyanira, el verbo nubeo.

${ }^{14}$ El caso de Deyanira no era desamor porque nunca se habían amado, en el caso de Cánace no es desamor porque ambos siguen amándose.

${ }^{15}$ Hijo de Aquiles.

${ }^{16}$ Se refiere a las mujeres troyanas que, tras la caída de Troya, se convirtieron en esclavas de los griegos.
} 
Pero tú, Orestes, si alguna piadosa preocupación sientes por mí,

lanza tus no cobardes manos a defender lo que es tuyo por derecho.

Pyrrhus Achillides, animosus imagine patris,

Inclusam contra iusque piumque tenet.

Quod potui, renui, ne non inuita tenerer;

Cetera femineae non ualuere manus.

«Quid facis, Aeacide? non sum sine uindice» dixi;

«Haec tibi sub domino est, Pyrrhe, puella suo».

Surdior ille freto clamantem nomen Orestae

Traxit inornatis in sua tecta comis.

Quid grauius capta Lacedaemone serua tulissem,

Si raperet Graias barbara turba nurus?

Parcius Andromachen uexauit Achaia victrix,

Cum Danaus Phrygias ureret ignis opes.

At tu, cura mei si te pia tangit, Oreste,

Inice non timidas in tua iura manus (Ov.Her.VIII.3-16).

Los argumentos a los que recurre nuestra heroína para persuadir a Orestes de que la rescate son legales y morales (Ov.Her.VIII.15-54). Ella no intenta convencerlo recurriendo al recuerdo de un pasado feliz, pues posiblemente no llegaron a estar casados ${ }^{17}$, o a la evocación de una futura felicidad amorosa $^{18}$, como hacen otras heroínas de la colección ${ }^{19}$. La voz de Hermione nos describe a una mujer que lleva un tiempo obligada a vivir con un hombre cruel con el que no quiere estar, una mujer que parece haber aprendido como modo de vida a ser lo menos infeliz posible dentro de la infelicidad en la que le ha tocado vivir. Esto podemos verlo en un verso en el que, con amarga autoironía, dice antitéticamente ${ }^{20}$ que, a pesar de ser infeliz, puede disfrutar durante el día de la ausencia de Pirro: «Aún así, cuando el alto Titán instiga a los brillantes caballos, / disfruto, infeliz, pues estoy más libre de mi desgracia» (Cum tamen altus equis Titan radiantibus instat, / perfruor infelix liberiore malo Ov.Her.VIII.105-106).

Sin embargo, pese a su infelicidad presente, la voz de Hermione, desde cierto idealismo romántico (Williams, 1997: 121), encierra cierta esperanza, y por ello escribe: espera librarse de Pirro y estar con Orestes. Ella reconoce que dentro de la mala suerte que ha tenido en su vida por haber crecido sin padre y sin madre ${ }^{21}$, había sido afortunada de ser entregada a Orestes, pero que ni siquiera eso pudo disfrutar pues finalmente fue a parar como un botín a las manos del violento Pirro: «Sólo esta parte tengo, me tocó por suerte Orestes como esposo; / y también este, si no luchara por lo que es suyo, me sería arrebatado» (Pars haec una mihi; coniunx bene cessit Orestes; / Is quoque, ni pro se pugnet, ademptus erit Ov.Her.VIII.101-102). Por ello con su discurso lucha por poder atrapar esa única cosa buena de su vida que quizás pueda traerle algo de felicidad, e intenta convencer a Orestes de que venga a rescatarla de Pirro.

\footnotetext{
${ }^{17}$ Es difícil saber con exactitud qué intertextos utilizaría Ovidio. Según las palabras de Hermione, parece que fue prometida a Orestes pero que no llegaron a casarse.

${ }^{18}$ Las referencias al amor entre Orestes y Hermione se reducen a una sola, que se encuentra en un verso (Ov.Her.VIII.37) en que el ella le intenta convencer de que su amor no sería mal visto para su padre Menelao, pero habla de un potencial amor que tendrían si Pirro la devolviera a Orestes. No utiliza una futura felicidad amorosa como argumento.

${ }^{19}$ Por ejemplo, Laodamía, como veremos.

${ }^{20}$ Yuxtaponiendo en un oxímoron 'disfruto' e 'infeliz' (perfruor infelix 106).

${ }^{21}$ Helena fue raptada por Paris cuando Hermione era un bebé, y su padre se fue a la guerra para recuperarla.
} 
Si Deyanira y Cánace recomendaban un 'buen matrimonio' como base para la felicidad, Hermione tiene un discurso más genérico que incluye otros factores a parte del matrimonio y que se acerca más al tópico del carpe diem de coger y aprovechar las cosas buenas dentro de la adversidad. Por ello, decide aprovechar lo poco que puede disfrutar en el presente, que es la ausencia de Pirro, y por ello intenta conseguir cierta felicidad luchando por el matrimonio no impuesto con Orestes que ahora ella elige. Algo que, por otro lado, Ovidio, desde la superioridad irónica de quien escribe una historia conociendo su final, sabe que conseguirá fuera de los límites de la carta, pues según la Andrómaca de Eurípides, Orestes mata finalmente a Pirro.

Ese acto casi desesperado de buscar la más mínima fuente de disfrute entre desgracias, también podemos verlo en la Heroida de Medea (Ov.Her.XII), aunque no con el tono idealista de Hermione sino con un tono de incipiente rabia. Medea, hija del rey de la Cólquide, después de traicionar a su patria para ayudar al griego Jasón a hacerse con el vellocino de oro y de huir para casarse con él, descubre que su marido la abandona para casarse con Creusa, la hija del rey de Corinto, Creonte, y beneficiarse del matrimonio real. Nuestra heroína escribe a Jasón poco después de que este se haya casado con Creusa. Es un momento desesperado para Medea, que de repente se encuentra sola y repudiada en un país extranjero, y encuentra en la escritura el único placer que el momento puede darle: el reproche. Medea le escribe a Jasón: «Hay cierto placer en echarle en cara los favores a un desagradecido; / disfrutaré de ello, solo ese gozo conseguiré de ti» (Est aliqua ingrato meritum exprobare uoluptas; / Hac fruar, haec de te gaudia sola feram Ov.Her.XII.21-22). Nuestra heroína ya se resigna a conseguir algún placer o alegría por parte de Jasón, y decide disfrutar del reproche como única forma de placer que la adversidad puede darle. El reproche a Jasón gira en torno a tres argumentos que recuerdan su pasado común: que nuestro héroe rompa el juramento que le hizo a la joven Medea de entregarle, solo a ella, su lecho; que ella haya traicionado y abandonado su patria por él y, por último, que Jasón esté vivo y en poder del vellocino solo gracias a Medea. Este incisivo recuerdo de lo que ha hecho por él configura el discurso de la Medea de la carta y resulta una herramienta para construir su dolor.

Encontramos por tanto un sentimiento positivo de placer unido al acto del reproche, pero también podemos encontrar en las antítesis de su dolor una proyección de la felicidad de Medea, pues la carta no es sólo reproche, sino que la voz de nuestra heroína dibuja un retrato muy concreto de su infelicidad, que no es por el desamor, sino por el arrepentimiento de haber confiado en un aliado que ahora la traiciona $^{22}$ :

\footnotetext{
Pero, recuerdo, yo, reina de los Colcos, estuve disponible para ti cuando pedías que mis artes te ayudaran.

Entonces las hermanas que administran las suertes humanas

deberían haber hilado mi destino ${ }^{23}$.

Entonces pude, Medea, morir feliz.

Todo lo que he me ha ocurrido desde ese momento de mi vida ha sido un castigo.
}

\footnotetext{
22 Para más información sobre el personaje de Medea en la Heroida XII, ver Blázquez Noya 2017a.

${ }^{23}$ Se refiere a las Parcas, que en la mitología grecolatina controlan la vida y la muerte de los mortales.
} 
At tibi Colchorum, memini, regina uacaui, Ars mea cum peteres ut tibi ferret opem.

Tunc, quae dispensant mortalia fata, sorores Debuerant fusos euoluisse meos.

Tum potui Medea mori bene. Quidquid ab illo Produxi vitae tempore, poena fuit (Ov.Her.XII.1-6).

Desearía que se hubiese enfrentado el ingrato Esónida ${ }^{24} \sin$ la protección de mis filtros a los alientos de fuego y a los curvados rostros de los bueyes.

Desearía que hubiese arrojado las semillas y recogido igual número de enemigos para que el cultivador hubiese muerto a manos de su propio cultivo ${ }^{25}$.

¡Cuánta traición junto contigo, criminal, habría desaparecido!

¡Qué gran cantidad de males se habrían apartado de mi cabeza!

Isset anhelatos non praemedicatus in ignes Inmemor Aesonides oraque adunca boum;

Semina iecisset, totidem sumpsisset et hostes, $V t$ caderet cultu cultor ab ipse suo.

Quantum perfidiae tecum, scelerate, perisset!

Dempta forent capiti quam mala multa meo! (Ov.Her.XII.15-20).

Hermione escribía a Orestes para que viniera a rescatarla, Deyanira para que repudiara a su amante Yole y volviera a ser un héroe para mantener ella su estatus de esposa del héroe. Medea escribe la carta principalmente para plasmar sus reproches, pero hay una parte que escribe la mujer abandonada que quiere recuperar su matrimonio, que al igual que Deyanira, no desea su amor, desea su posición de esposa del héroe, algo que ella se ha ganado al salvarle la vida y conseguirle el vellocino. De sus palabras se desprende que Medea se siente su compañera, su socia, poseedora por derecho propio de todo lo que tiene Jasón, de su fama y de su honor, y al quitarle el nombre de esposa también le está quitando todo eso, que ella desea y merece.

Te suplico por los dioses, por la luz de las llamas de mi abuelo ${ }^{26}$, por mis méritos y por nuestros dos hijos, prendas de nuestra alianza, devuélveme el lecho por el que tantas cosas, insensata, he abandonado.

No te imploro que te enfrentes a toros y hombres

ni que la serpiente duerma vencida por tus propios medios.

Te reclamo a ti, al que he merecido, a quien tú mismo me entregaste,

con quien he sido madre a la vez que tu padre.

Per superos oro, per auitae lumina flammae,

Per meritum et natos, pignora nostra, duos,

Redde torum, pro quo tot res insana reliqui.

Adde fidem dictis auxiliumque refer.

Non ego te imploro contra taurosque uirosque,

Vtque tua serpens uicta quiescat ope;

Te peto, quem merui, quem nobis ipse dedisti,

Cum quo sum pariter facta parente parens (Ov.Her.XII.191-198).

\footnotetext{
${ }^{24}$ Jasón.

${ }^{25}$ Medea se refiere a las pruebas que el rey de la Cólquide estableció para Jasón como condición para entregarle el vellocino.

${ }^{26}$ Helios, el Sol, es el abuelo de Medea.
} 
Medea es por tanto una mujer abandonada, pero esta caracterización resulta muy simplista si olvidamos el mencionado factor clave: su sentimiento de culpa por haber traicionado a su familia y a su reino por un hombre que ha traicionado abandonándola. La necesidad de apaciguar su ánimo y el dolor por la traición de su esposo resultan más poderosos que su necesidad de recuperarlo y por ello no utiliza un lenguaje de seducción sino que lo ataca duramente e incluso lo amenaza, esperando a su vez que, haciéndolo sentir culpable, vuelva con ella.

Que estés vivo, que tengas una novia y un suegro poderosos,
y el propio hecho de que puedas ser ingrato, me pertenece.
A estos sin duda pronto... ¿pero qué interés tiene anunciar de antemano
el castigo? Mi ira engendra grandes amenazas.
Iré donde me lleve la ira. Quizás me arrepienta de hacerlo;
Desde luego me arrepiento de haber ayudado a un hombre desleal.
Verá esto el dios que ahora habita mi pecho.
Mi mente trama un 'no sé qué' muy terrible.
Quod uiuis, quod habes nuptam socerumque potentes,
Hoc ipsum, ingratus quod potes esse, meum est.
Quos equidem actutum... Sed quid praedicere poenam
Attinet? Ingentis parturit ira minas.
Quo feret ira, sequar. Facti fortasse pigebit;
Et piget infido consuluisse uiro.
Viderit ista deus, qui nunc mea pectora uersat.
Nescio quid certe mens mea maius agit (Ov.Her.XII.205-212).

Ovidio nos presenta así a una Medea que en la carta explora su culpabilidad, clara fuente de su infelicidad. Por todo lo dicho, sólo hay tres condiciones que podrían acabar con el dolor de Medea. La primera es utópica y fruto de su arrepentimiento: de no haber ayudado a Jasón, Medea sería feliz quedándose en su reino. Recuerda así el tiempo en que era una muchacha inocente y feliz (Ov.Her.XII.1-6). La segunda es una condición improbable y contradictoria: que Jasón vuelva a aceptarla como esposa. Esto es algo que su voz llena de rabia apenas le deja desear, y sólo dedica unos pocos versos a esta petición en un intento desesperado de no tener que recurrir al último recurso que pueda traerle paz (Ov.Her.XII.191-198). Nos referimos a la venganza de Medea $^{27}$. La idea de la venganza para recuperar su honor perdido y así poder serenar su alma en la carta aún no se ha gestado pero empieza a gestarse (Ov.Her.XII.205-212), y no se desarrollará en la carta sino en los hechos posteriores de su historia que recogen obras como la Medea de Eurípides, entre otras. Encontramos asî una voz que escribe en un momento de máxima tensión emocional y que vacila entre varios sentimientos.

Por último, recogeremos el ejemplo de felicidad más esperado para una carta de amor que la heroína escribe a su amado ausente. La Heroida de Laodamía a Protesilao (Ov.Her.XIII) es una de las cartas más propiamente de amor de toda la colección, pues tenemos a una pareja de recién casados que se han visto separados cuando él ha sido reclutado para luchar en la Guerra de Troya. El sufrimiento de Laodamía es el provocado por la reciente separación y por el temor a la muerte del amado en la

\footnotetext{
${ }^{27}$ Medea ejecutará a los hijos que ha tenido con Jasón.
} 
guerra. Es por tanto un sufrimiento causado por las convenciones sociales que obligan a su marido a participar en la guerra, no por un abandono intencionado:

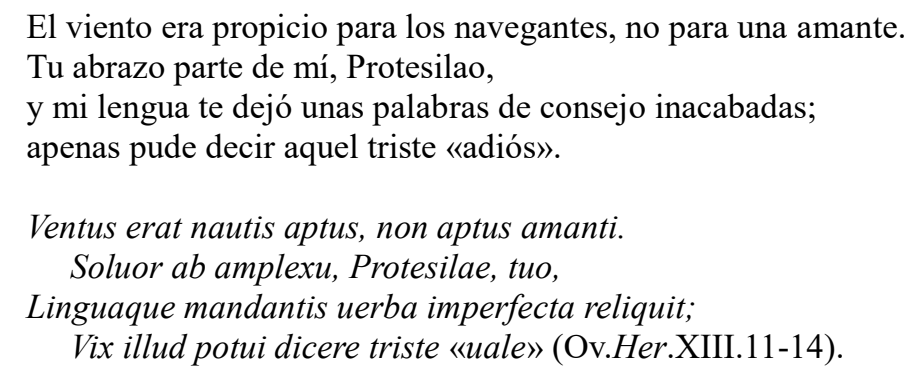

Laodamía ama a su marido. Protesilao no es un héroe, de modo que no quiere compartir su gloria, como hace Deyanira con Hércules. De hecho, incluso desearía que no fuera a la guerra y le disuade de ser demasiado valiente en la lucha:

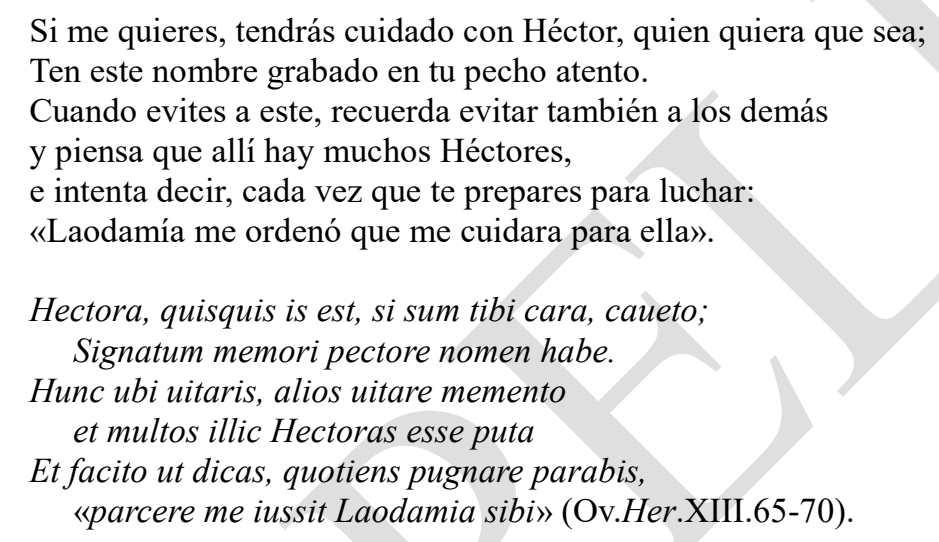

Laodamía y Protesilao no se han casado para establecer una alianza, como Medea y Jasón, como Deyanira y Hércules, como Hermione y Pirro, sino por simple amor. En la carta hay grandes muestras de cariño, como los besos que quiere haber dado y dar a su marido ( «Habría dado a mi marido muchos besos y muchos consejos», Oscula plura uiro mandataque plura dedissem Ov.Her.XIII.7; «Recibirás muchos besos y muchos besos darás», Multa tamen rapies oscula, multa dabis Ov.Her.XIII.118). Laodamía no ha podido disfrutar de una primera etapa feliz en el matrimonio, como otras esposas enamoradas de la mitología (Esteban Santos, 2006: 97). Por eso la felicidad de Laodamía, que es una felicidad amorosa, es proyectada por su voz en el deseo de la vuelta sano y salvo de su marido, como se puede ver en su descripción del futuro reencuentro de los amantes, un tópico habitual en la poesía amorosa: «¿Cuándo, abrazándote a tu vuelta con mis deseosos brazos, sin fuerzas desfalleceré yo por mi propia alegría?»(Quando ego, te reducem cupidis amplexa lacertis, / languida laetitia soluar ab ipsa mea? Ov.Her.XIII.113-114).

Sin embargo, ese deseado reencuentro que le devolvería la felicidad a Laodamía nunca se materializará, pues Protesilao, según la tradición, será el primer griego en morir al llegar a Troya, y Laodamía, al conocer la noticia, se suicidará ${ }^{28}$. Fulkerson (2005), que concibe la colección de las

\footnotetext{
${ }^{28}$ La muerte de Laodamía se produce de diferentes maneras según la tradición mitológica (Fulkerson, 2002: 78).
} 
Heroidas como una colección de poemas escritos por mujeres que se leen unas a otras, reflexiona sobre que muchos de los finales de las historias de las heroínas no son 'finales felices', precisamente porque el conocimiento previo de la historia prefijada limita las posibilidades de estas mujeres excluyendo de entrada su 'final feliz', y que de esta manera se incluyen en una larga tradición de 'poetas miserables' (Fulkerson, 2005: 6,16). Sin duda Deyanira, Cánace y Laodamía no conseguirán su 'final feliz', puesto que ante la desgracia ellas se suicidan.

En las voces de Deyanira, Cánace, Hermione, Medea y Laodamía hemos encontrado algunas muestras de recuerdos de felicidad pasada, de evocaciones de la felicidad deseada, y de formas de disfrutar del presente desgraciado. Hemos visto qué factores les traen la infelicidad a nuestras heroínas: a Deyanira un mal marido, a Cánace una pareja indecorosa, a Hermione un marido forzoso, a Medea un aliado ingrato, a Laodamía un marido-amante ausente. Las relaciones con los hombres, de diversa índole, no siempre amorosa, son causa de su sufrimiento. En dos de los casos, Medea y Deyanira, el matrimonio es el logro que les trae la gloria, y ninguna de las dos está dispuesta a perderla. En el caso de Hermione, su matrimonio con Pirro es causa de esclavitud y el matrimonio con Orestes un símbolo de su potencial libertad de toma de decisiones. A Cánace su padre le obliga al suicidio al conocer su unión mal vista, incestuosa. Y Laodamía es la única que sufre por no poder estar con su marido amado. Así, las protagonistas de las Heroidas están sumidas en profundos sufrimientos y dolores, cada uno provocado por su propia causa: el amor, el mal matrimonio, las convenciones sociales, la traición, la culpa. Pero es ese mismo sufrimiento el que provoca antitéticamente que las heroínas reflexionen sobre lo que ha sido o sería la felicidad para ellas, o las incita a que busquen o aprovechen esa cierta alegría a la que pueden acceder. Parece que Ovidio no permite que sus desdichadas heroínas olviden la felicidad.

\section{Referencias bibliográficas}

BARCHIESI, A. (2001): «Narrativity and Convention in the Heroides», en M. Fox y S. MARCHESI, eds., Speaking Volumes. Londres, Duckworth, pp. 29-47.

BlÁzquez Noya, A. (2015): «Las voces de Deyanira en Heroidas IX de Ovidio y Traquinias de Sófocles», Myrtia, 30, pp. 11-33.

(2017a): «Medea en Heroidas XII: una heroína elegíaca», Conventus Classicorum (Vol. I), pp. $769-776$.

(2017b): «El "travestimiento burlesco" de Hércules en Ov. Her. IX. (55-118)», Studia Philologica Valentina, Anejo 1 (2017), pp. 87-94.

BREMOND, C. (2003): «Concepto y tema», en C. NAUPERT, comp., Tematología y comparatismo literario. Madrid, Arco.

CASALI, S. (1995): «Tragic irony in Ovid, Heroides 9 and 11”, CQ, 45, pp. 505-511. 
CORTÉS TOVAR, R. (2012): «QUA licet et sequitur pudor est miscendus amori (OV.epist.4.9): la transgresión de los límites y los límites de la transgresión en la carta de Fedra», $C F C(L)$ 32/2, pp. 247-269.

EsteBAn SANTOS, A. (2006): «Esposas en guerra (esposas del ciclo troyano). Heroínas de la mitología griega II», $C F C(G), 16$, pp. 85-106.

FUlKerson, L. (2002): «(Un)Sympathetic Magic: A Study of Heroides 13», AJPh, 123/1, pp. 61-87.

- (2005): The Ovidian Heroine as Author: Reading, Writing and Community in the Heroides. Cambridge, Cambridge University Press.

GONZÁlEZ GARCíA, J. (1996): «Mito e ideología: supremacía masculina y sometimiento femenino en el mundo griego antiguo», en J. BERMEJO et al., Los orígenes de la mitología griega. Madrid, Akal, pp. 163-174.

JACOBSON, H. (1974): Ovid's Heroides. Princeton, Princeton University Press.

Jolivet, J. C. (2001): Allusion et fiction épistolaire dans les Hérö̈des: Recherches sur l'intertextualité ovidienne, Paris-Roma, Ecole Francaise de Rome.

Kenney, E. J. (1982): «Ovid», en E. J. Kenney y W. V. Clausen, The Cambridge History of Classical Literature II: Latin Literature. Cambridge, Cambridge University Press, pp. 420-457.

LindHeIM, S. H. (2003): Mail and Female. Epistolary Narrative and Desire in Ovid's Heroides. Wisconsin, University of Wisconsin Press

MoYA, F., ed. (1986): Ovidio. Heroidas. Madrid, CSIC.

Murgatroyd, P. (2014): «Ovid's Hermione: A kaleidoscopic heroine», Classical Quarterly, 64/2, pp. 850-853.

Rosati, G. (1993): «L'elegia al femminile: le Heroides di Ovidio (e altre heroides)», MD, 29, pp. 7174.

SPEntzou, E. (2003): Readers and Writers in Ovid's Heroides. Transgressions of Genre and Gender. Oxford, Oxford University Press.

Williams, G. (1997): «Writing in the Mother-Tongue: Hermione and Helen in Heroides 8 (A Tomitan Approach)», Ramus, 26/2, pp. 113-137. 